\title{
B7-H3 is related to tumor progression in ovarian cancer
}

\author{
JINGJING ZHANG ${ }^{1}$, LU LIU ${ }^{1}$, SAI HAN ${ }^{1}$, YI LI $^{1}$, QIUHONG QIAN ${ }^{1}$, \\ QIANQIAN ZHANG ${ }^{1,2}$, HUI ZHANG ${ }^{2}$, ZIYAN YANG ${ }^{1}$ and YOUZHONG ZHANG ${ }^{1}$ \\ ${ }^{1}$ Department of Obstetrics and Gynecology, Qilu Hospital of Shandong University, Jinan; ${ }^{2}$ Department of Obstetrics \\ and Gynecology, The Affiliated Hospital of Taishan Medical College, Taian City, Shandong, P.R. China
}

Received March 23, 2017; Accepted July 20, 2017

DOI: 10.3892/or.2017.5858

\begin{abstract}
B7-H3, a co-stimulatory molecule, has been found expressed in ovarian cancer, but its role and mechanism is not clear. In this study, we further verified the expression of B7-H3 in ovarian carcinoma and normal epithelial ovarian tissues. Three ovarian cancer cell lines, A2780, SKOV3 and HO8910 were selected to explore the effects of B7-H3 on proliferation, apoptosis, migration and invasion. We found that B7-H3 was mainly located in the cytoplasm of ovarian cancer cells as determined by immunofluorescence staining. The ability of cell invasion, migration, proliferation decreased after silencing B7-H3 whereas the apoptosis increased, which was related to the upregulation of Bax, caspase-8, cleaved caspase- 8 and the downregulation of $\mathrm{Bcl}-2, \mathrm{Bcl}-\mathrm{xl}$, matrix metalloproteinase-2 (MMP2) by western blotting. In addition, B7-H3 enhanced the H08910 cell capacities in invasion, migration and proliferation. Expression of the phosphorylation signal transducer and activator of transcription 3 (pStat3) molecules and their upstream molecules phosphorylation Janus kinase 2 (pJak2) were significantly increased. In order to investigate whether B7-H3 plays a role in this pathway, we treated the overexpressed HO8910 cells with AG490 (inhibitors of Jak2). Our findings revealed that $\mathrm{B} 7-\mathrm{H} 3$ affect ovarian cancer progression through the Jak2/Stat 3 pathway, indicating that B7-H3 has the potential to be a useful prognostic marker.
\end{abstract}

\section{Introduction}

Ovarian cancer is the most lethal gynecological malignancy and the fifth most common cause of cancer death among women, $90 \%$ is epithelial ovarian cancer (EOC) (1). The early diagnosis of ovarian cancer is not perfect so that the majority of patients are diagnosed with advanced disease, and

Correspondence to: Dr Youzhong Zhang, Department of Obstetrics and Gynecology, Qilu Hospital of Shandong University, 107 Wenhua Xi Road, Jinan, Shandong 250012, P.R. China

E-mail: zhangyouzhong@sdu.edu.cn

Key words: $\mathrm{B} 7-\mathrm{H} 3$, ovarian cancer, invasion, migration, proliferation, apoptosis, Jak2-Stat3 pathway the five-year survival rate for EOC is approximately $30 \%$ (2). Therefore it is necessary to find specific diagnostic methods and therapeutic approaches for ovarian cancer.

B7-H3 is encoded by the CD276 gene, including two main isoforms, named 4Ig-B7-H3 and 2Ig-B7-H3, which were first identified in $2001(3,4)$. A newly found member of B7/CD28 family, and was identified as an accessory co-stimulatory molecule after initial antigen priming in cooperation with a putative counter receptor (5). Recently, a number of articles have reported that B7-H3 is highly expressed in many cancers, including colorectal cancer (6), hepatocellular carcinoma (7), lung cancer (8), gastric cancer (9), breast cancer (10) and prostate cancer (11). In addition, B7-H3 has been shown to be associated with poor prognosis by the Jak2/Stat 3 pathway. Although the expression of $\mathrm{B} 7-\mathrm{H} 3$ in ovarian cancer was mentioned in a document, it was verified only at the tissue level that the high expression of B7-H3 in ovarian cancer and B7-H3-positive tumor vasculature is associated with high-grade serous histological subtype, increased recurrence and reduced survival (12). There is no study on the biological behavior and mechanism of the cells. Thus in this study, we show how B7-H3 affects the biological behavior of the cells and its mechanism.

\section{Materials and methods}

Patients and tissue samples. Ovarian cancer tissue samples were collected from 41 patients who underwent surgery from 2015 to 2016 in Qilu Hospital of Shandong University. In addition, 31 normal ovarian tissues were collected to use as control. None of the patients received preoperative chemotherapy or radiotherapy before the surgery. All patients were confirmed by pathological diagnosis. The present study was approved by the Ethics Committee of Qilu Hospital.

Cell lines and cell culture. The human ovarian cancer cell lines A2780, SKOV3, and HO8910 were purchased from the American Type Culture Collection (ATCC; Manassas, VA, USA). A2780 and HO8910 were cultured in the medium of Roswell Park Memorial Institute (RPMI)-1640 (Hyclone Laboratories, Logan, UT, USA), while SKOV3 in the medium of Micro-5A (Gibco-Invitrogen, Grand Island, NY, USA). All of them were supplemented with $10 \%$ fetal bovine serum (FBS; Gibco, Sydney, Australia) and incubated at $37^{\circ} \mathrm{C}$ in a humidified incubator supplemented with $5 \% \mathrm{CO}_{2}$. 
Antibodies and reagents. Rabbit anti-human Jak2, Phospho-Jak2 (Tyr1007), signal transducer and activator of transcription 3 (Stat3), phospho-Stat3 (Tyr705), Bcl-2 and Bax antibodies were purchased from Abcam (Cambridge, MA, USA). Mouse anti-human Bcl-xl, caspase- 8 and MMP-2 were obtained from Santa Cruz Biotechnology (Dallas, TX, USA). Rabbit anti-human B7-H3, cleaved caspase- 8 and the GAPDH were purchased from Cell Signaling Technology (CST) (Danvers, MA, USA). All of the above are monoclonal antibodies. Tryphostins AG490 was from Abcam and prepared at a concentration of $100 \mathrm{mmol} / \mathrm{l}$ stock solution in dimethyl sulfoxide (DMSO).

Immunohistochemical analysis. Polink-2 Plus Polymer HRP Detection System (ZSGB-BIO, Beijing, China) was used. Paraffin tissues were cut into $4-\mu \mathrm{m}$ sections. Section were de-paraffinized in xylene, re-hydrated through a graded ethanol series, then repaired by citric acid (microwave boiling method). $\mathrm{H}_{2} \mathrm{O}_{2}$ (3\%) was incubated for 10 min to block endogenous peroxidase activity. PBS (phosphate-buffered saline) was used for washing three times for 3 min each. After blocking endogenous peroxidase activity, the slides were incubated with primary antibody overnight at $4^{\circ} \mathrm{C}$. The next day, sections were washed in PBS three times for $5 \mathrm{~min}$ each. Secondary antibody was applied for $30 \mathrm{~min}$ at $37^{\circ} \mathrm{C}$. DAB was used for coloring. Finally slides were counterstained with water rinsing, staining, dehydration, transparent and mounting. Quantification was recorded as follows: $<10 \%$ positive cells, $0 ; 10-25 \%, 1 ; 26-50 \%, 2 ;>50 \%$ positive cells, 3 . Sections with a final score of $0-1$ was classified as negative, and $\geq 2$ was considered positive.

Immunofluorescence staining. To find the $\mathrm{B} 7-\mathrm{H} 3$ expression location, the A2780 and SKOV3 cells were seeded in a 24-well plate at $37^{\circ} \mathrm{C}$ overnight. Then, after three washes with PBS, the cells were fixed with $4 \%$ paraformaldehyde for $15 \mathrm{~min}$ at room temperature, and permeabilized with $0.2 \%$ Triton $150-200 \mu 1$ in PBS for 10 min. After that, the B7-H3 (1:200 dilution) antibody was incubated at $4^{\circ} \mathrm{C}$ for overnight and secondary antibody (1:200) for $1 \mathrm{~h}$. Finally, cells were stained with 4,6-diamidino-2-phenylindole (DAPI) for $5 \mathrm{~min}$ in the dark at room temperature. The fluorescence images were observed using a fluorescence microscope (Olympus, Tokyo, Japan).

Silencing and overexpression of B7-H3. Silencing or overexpression of B7-H3 sequences were designed by GenePharma Co, Ltd. (Shanghai, China). The cells were seeded in 6-well plates, $24 \mathrm{~h}$ after the cell attachment, the virus liquid was mixed in the culture medium. The cells were screened with puromycin dihydrochloride $(2 \mu \mathrm{g} / \mathrm{ml}$; Amresco, Solon, $\mathrm{OH}$, USA) $72 \mathrm{~h}$ later. After screening for 5-7 days, the cell line with stable overexpression of B7-H3 (HO8910-B7-H3-EGFP) and their control cell lines (HO8910-NC) were obtained. The A2780 and SKOV3 cells were seeded in a 6-well plate with $3 \times 10^{4} / \mathrm{ml}$ cell per well, $24 \mathrm{~h}$ later, cells were transfected with $50 \mathrm{nM}$ of the Sh-B7-H3 or control sequences using Lipofectamine-2000 (Invitrogen Life Technologies). The transfected cells were harvested $48 \mathrm{~h}$ post-transfection for the follow-up experiments, with A2780-NC, A2780-sh-B7-H3, SKOV3-NC and SKOV3-sh-B7-H3.
Table I. Relationship between B7-H3 expression on tumor cells and clinicopathological factors.

\begin{tabular}{|c|c|c|c|c|}
\hline \multirow[b]{2}{*}{ Factors } & \multirow[b]{2}{*}{ No. } & \multicolumn{2}{|c|}{$\begin{array}{c}\text { Expression } \\
\text { of B7-H3 }\end{array}$} & \multirow[b]{2}{*}{ P-value } \\
\hline & & Negative & Positive & \\
\hline B7-H3 & & & & $<0.0001$ \\
\hline Ovarian cancer tissue & 41 & 11 & 30 & \\
\hline Normal ovarian tissue & 31 & 24 & 7 & \\
\hline Age (years) & & & & 0.195 \\
\hline$\leq 50$ & 16 & 2 & 14 & \\
\hline$>50$ & 25 & 9 & 16 & \\
\hline Size $(\mathrm{cm})$ & & & & 0.903 \\
\hline$\leq 5$ & 18 & 5 & 13 & \\
\hline$>5$ & 23 & 6 & 17 & \\
\hline Histology & & & & 0.920 \\
\hline Serous CA & 28 & 7 & 21 & \\
\hline Endometrioid CA & 7 & 1 & 6 & \\
\hline Vascular Invasion & & & & 0.300 \\
\hline- & 36 & 11 & 25 & \\
\hline+ & 5 & 0 & 5 & \\
\hline Distant metastasis & & & & 0.041 \\
\hline- & 14 & 7 & 7 & \\
\hline+ & 27 & 4 & 23 & \\
\hline Differentiation & & & & 1.000 \\
\hline Low & 2 & 0 & 2 & \\
\hline Moderate/high & 33 & 8 & 25 & \\
\hline Clinical stage & & & & 0.057 \\
\hline $\mathrm{I} / \mathrm{II}$ & 13 & 6 & 7 & \\
\hline III/IV & 28 & 5 & 23 & \\
\hline
\end{tabular}

Values in bold, $\mathrm{P}<0.05$.

Western blot assay. The cells were washed 3 times with PBS and then lysed on ice for approximately $30 \mathrm{~min}$. The pyrolysis solution is composed of radio immunoprecipitation assay buffer (RIPA), phenylmethylsulfonyl fluoride (PMSF) and $\mathrm{NaF}$. The cells were then lysed with ultrasound. Cells were centrifuged at $12000 \mathrm{rpm}$ at $4^{\circ} \mathrm{C}$, then supernatant were drained, loading buffer was added and heated for $5 \mathrm{~min}$ in metal bath. The protein concentrations were measured by using the BCA Protein Assay kit (Beyotime, Jiangsu, China). Total protein $(30-50 \mu \mathrm{g})$ was separated by SDS-polyacrylamide gel electrophoresis (SDS-PAGE) in 10\% gels (Invitrogen) and transferred to PVDF membranes (ImmobilonP; Millipore, Bedford, MA, USA). After blocking with 5\% skim milk for $2 \mathrm{~h}$, the membranes were cut into strips and incubated with the indicated primary antibodies overnight at $4{ }^{\circ} \mathrm{C}$. The next day, the membranes were washed 3 times with TBS-T ( $20 \mathrm{mM}$ Tris, $\mathrm{pH} 7.4,137 \mathrm{mM} \mathrm{NaCl}, 0.05 \%$ Tween-20) and then indicated with secondary antibodies at room temperature for 1-2 $\mathrm{h}$. Ultimately, the immunoreactive protein bands were detected 
A

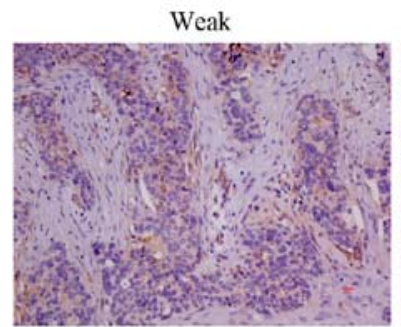

B
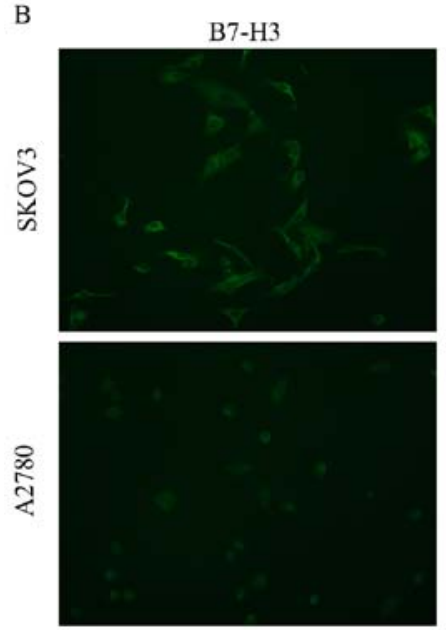

Moderate

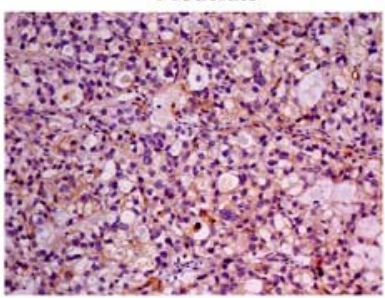

DAPI
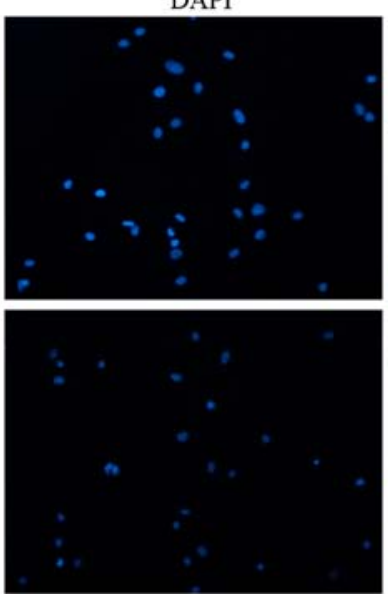
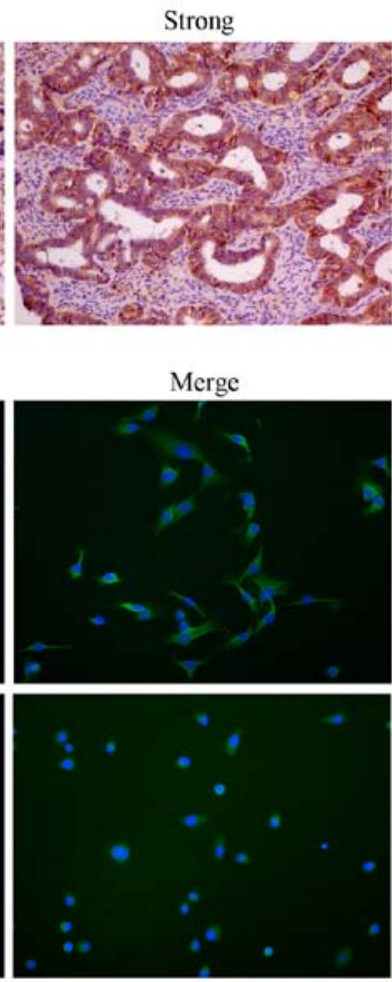

Figure 1. B7-H3 expression in ovarian tissues and its expression location. B7-H3 immunostaining in ovarian cancer tissues (A) Weak positive, moderate positive, strong positive (magnification, x200). (B) B7-H3 was stained in the cytoplasm of cells, while DAPI was stained in the nucleus (magnification, x200).

by enhanced chemiluminescence (ECL) using ImageQuant LAS 4000 (GE Healthcare Life Sciences, Logan, UT, USA). The results were analyzed by ImageJ software (NIH, Bethesda, MD, USA).

Cell proliferation assay. The cell proliferation was evaluated by MTT assay. In brief, cells were seeded in 96-well plates at 2000 cells per well. At indicated time-points, the cells in the 96-well plate were incubated with $20 \mu \mathrm{MTT}$ at $37^{\circ} \mathrm{C}$ for $4 \mathrm{~h}$. The cell growth was monitored every $24 \mathrm{~h}$ for up to 5 days. Absorbance was measured for each well at a wavelength of $490 \mathrm{~nm}$ using a microplate reader (Infinite 2000; Tecan, Männedorf, Switzerland).

Cell migration and invasion assays. For the in vitro migration and invasion assays, $3-5 \times 10^{4}$ cells of the A2780, HO8910 or SKOV3 derived cell cultures, in serum-free RPMI and Micro-5A medium, were seeded into the top of $8 \mu \mathrm{m}$ pore size transwell chambers (Costar, Cambridge, MA, USA), which contained $100 \mu \mathrm{l}$ of Matrigel (1:8 dilution in serum-free medium; Corning Inc., Corning, NY, USA) or not. Then the chambers were put into the 24-well plates which included culture medium with $10 \%$ serum. After incubation at $37^{\circ} \mathrm{C}$ for $24 \mathrm{~h}$ in a $5 \% \mathrm{CO}_{2}$ atmosphere, the cells were stained with $0.1 \%$ crystal violet and then washed 3 times with PBS. The images were captured by the Olympus IX51 inverted microscope. The number of migrating and invading cells on the chambers were counted in 5 random fields per chamber at x200 magnification of each group.

Cell cycle and apoptosis assays. To analyze the effect of B7-H3 on the different phases of the cell cycle and apoptosis, flow cytometry was used. Cells were harvested from each sample then fixed with cold $75 \%$ ethanol at $4^{\circ} \mathrm{C}$ overnight. The cells were washed 3 times and stained for $30 \mathrm{~min}$ in propidium iodide (PI) staining solution in the dark. The cell cycle was detected by FACSCalibur flow cytometer (both from BD Biosciences, Franklin Lakes, NJ, USA) and analyzed by ModFit LT software. For apoptosis, cells were harvested and processed as described in the Annexin V-fluorescein isothiocyanate (FITC) Apoptosis Detection kit I manual (BD Transduction Laboratories, BD Biosciences) and analyzed by flow cytometry (BD LSR II).

Statistical analysis. The data were analyzed using GraphPad Prism version 5.01 (GraphPad Software Inc., San Diego, CA, USA). The experiment was performed a minimum of three times, and all data are shown as means with standard deviations (SDs). The data were analyzed for statistical significance using an unpaired Student's t-test or a Chi-squared test. $\mathrm{P}$-value at $<0.05$ difference was considered to be statistically significant.

\section{Results}

B7-H3 expression in clinical specimens and the location of B7-H3 in ovarian cancer cell lines. In order to find out the expression of B7-H3 in ovarian cancer and the location of B7-H3, we used immunohistochemistry and immunofluorescence methods. Immunohistochemistry was performed to detect the expression of B7-H3 in 41 cases of ovarian cancer tissues and 31 cases of normal ovarian tissues. Although no expression or low expression of B7-H3 can be found in ovarian cancer and there are some weak expression in normal tissues 
A

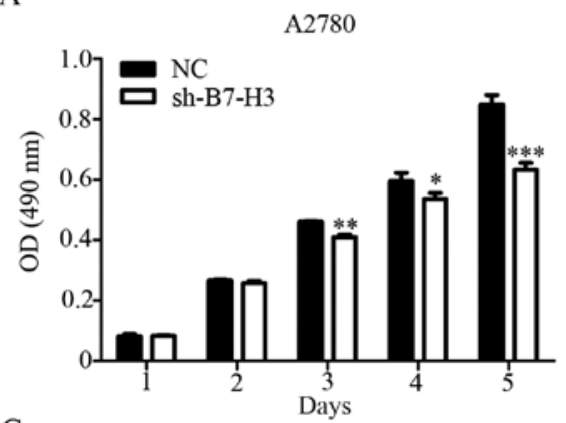

B

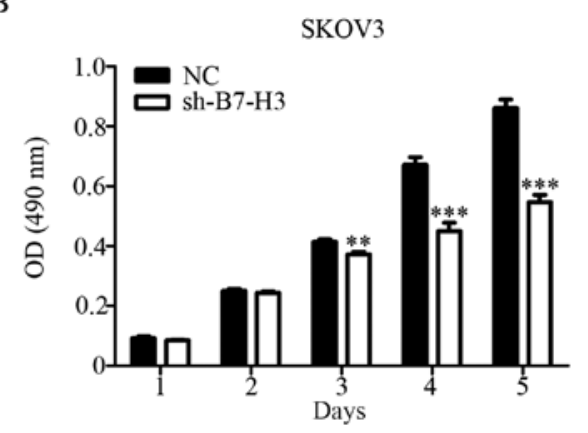

C

$\mathrm{NC}$

sh-B7-H3
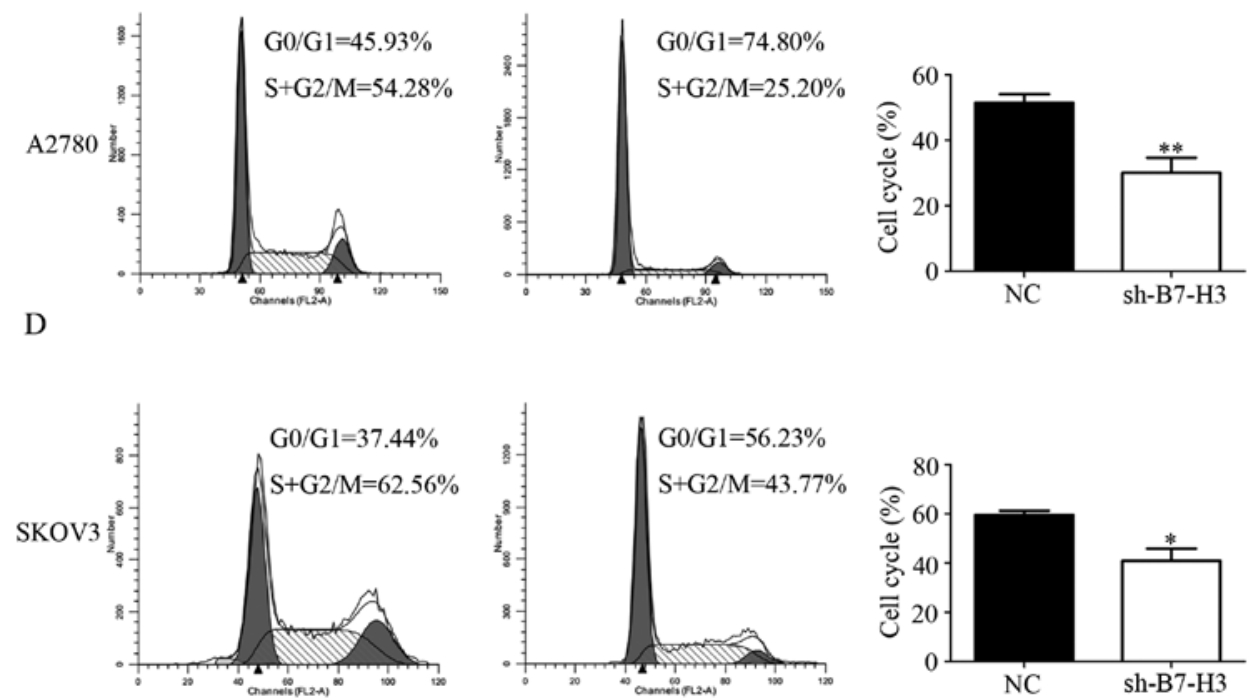

Figure 2. Effect of silencing B7-H3 on cell proliferation. (A and B) The cell viability of sh-B7-H3 group and NC group was tested at $24 \mathrm{~h}, 2,3,4$ and 5 days by MTT assay. (C and D) A flow cytometry was used to detect the cell cycle of cells treated with stable silencing and the percentage of the S and G1/G2 phases in the cell cycle is used to indicate cell proliferation; ${ }^{*} \mathrm{P}<0.05,{ }^{* *} \mathrm{P}<0.01,{ }^{* * *} \mathrm{P}<0.001$ compared with the control groups.

(Fig. 1A), the results showed that the expression of B7-H3 in ovarian cancer was significantly higher than that in normal tissues $(\mathrm{P}<0.001)$ (Table I). Immunohistochemistry revealed that $\mathrm{B} 7-\mathrm{H} 3$ was expressed in the cytoplasm of the tissue, and a few were expressed in the interstitial tissue. In order to clarify the localization of B7-H3, immunofluorescence was utilized and the results showed that $\mathrm{B} 7-\mathrm{H} 3$ was mostly expressed in the cytoplasm of ovarian cancer cells (Fig. 1B).

B7-H3 expression in relation to patient clinicopathological factors. The relationship between clinicopathological factors and $\mathrm{B} 7-\mathrm{H} 3$ expression in patients with ovarian cancer is shown in Table I. Our data suggest that B7-H3 expression is associated with distant metastasis of ovarian cancer $(\mathrm{P}=0.041)$, whereas it is not correlated with patient age $(\mathrm{P}=0.195)$, tumor size $(\mathrm{P}=0.903)$, tumor histology type $(\mathrm{P}=0.920)$, differentiation degree $(\mathrm{P}=1.000)$, clinical stage $(\mathrm{P}=0.057)$, and vascular invasion $(\mathrm{P}=0.300)$. However, in this study the number of cases is too small, therefore, in order to further clarify the relationship between B7-H3 and the clinicopathological characteristics of patients the number of samples should be increased.

Silencing B7-H3 weakens cell proliferation. To characterize the role of B7-H3 in A2780 and SKOV3 cell growth we measured the cell proliferation rate in vitro by MTT assay (11). The experiment was divided into two groups: NC group and sh-B7-H3 group. The results suggest that the cell viability of sh-B7-H3 group was weakened at 3,4 and 5 days compared with the NC group (Fig. 2A and B). Similar results were also found in the cell cycle (Fig. 3C and D). Compared with the control group, A2780 and SKOV3 cell lines that interfered with B7-H3 decreased the S and G2/M phases of the cell cycle, which was a period of cell proliferation ability. Thus, B7-H3 molecule expressed in ovarian cancer cells might play an important role in regulating the colony formation ability.

Silencing B7-H3 increases cell apoptosis. To verify the effect of B7-H3 on cell apoptosis after B7-H3 interference, we performed flow cytometry. The extent of apoptosis was investigated by measuring the amount of Annexin V stained cells, a marker for early stage apoptosis. The amount of all reagentpositive cells, which reflect the late stage apoptosis, were also measured. We found that when B7-H3 affected the early stage apoptosis of A2780 and SKOV3 cells were increased, and the late stage apoptosis although increased, was $\mathrm{P}>0.05$ (Fig. 3A and B). Therefore, B7-H3 mainly promotes apoptosis of cells through the early stage apoptosis. In addition, we observed 
A

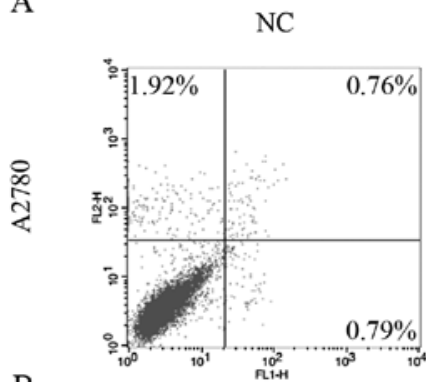

B

$\mathrm{NC}$

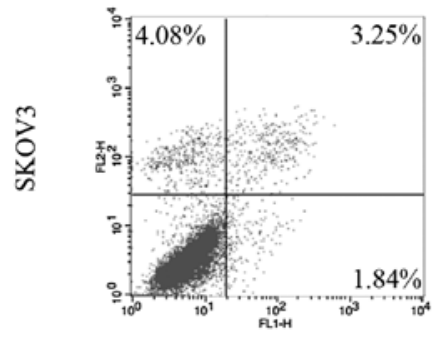

si-B7-H3

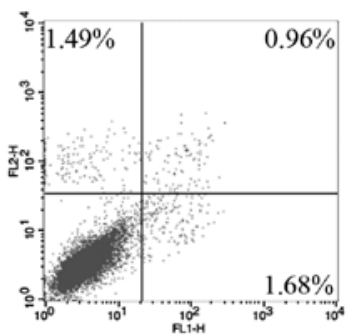

si-B7-H3

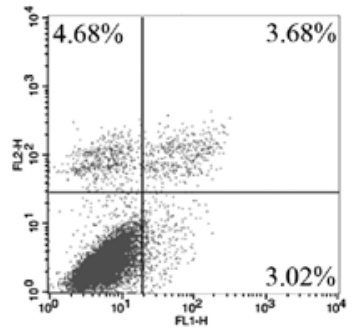

C
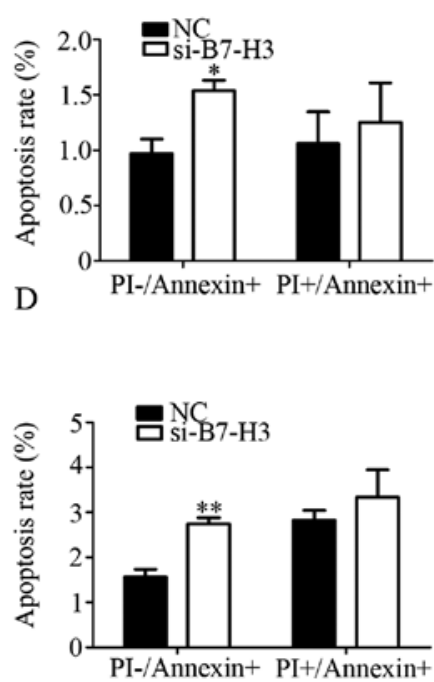

Figure 3. Effect of B7-H3 on cell apoptosis. (A and B) Knockdown of B7-H3 by siRNA induced apoptosis of the A2780 cell line and SKOV3 cell line. (C and D) Early apoptosis was used to express the apoptosis rate that is shown in (A and B).

A

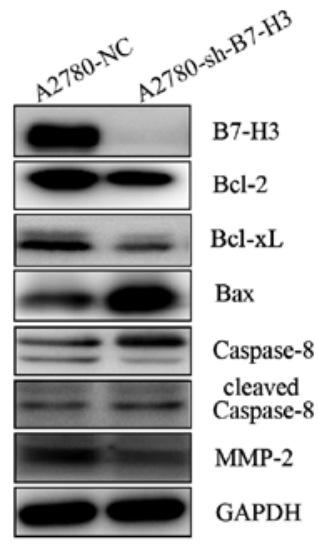

B

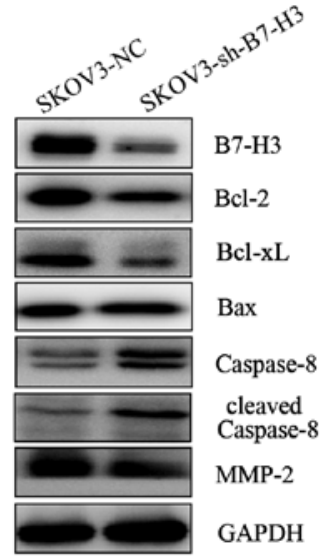

C

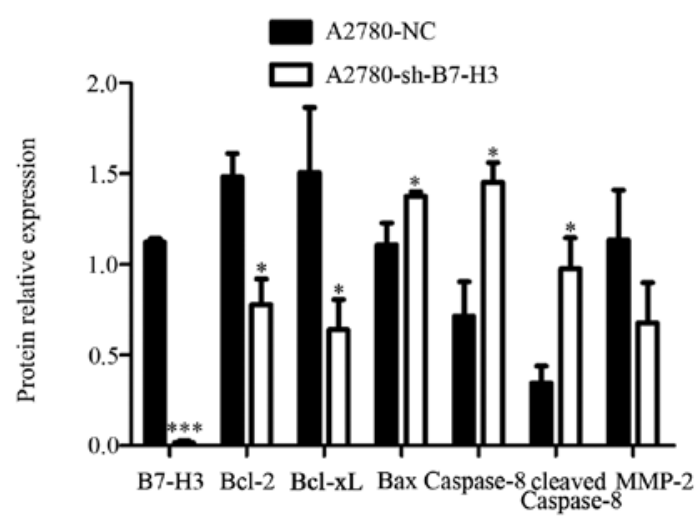

$\mathrm{D}$

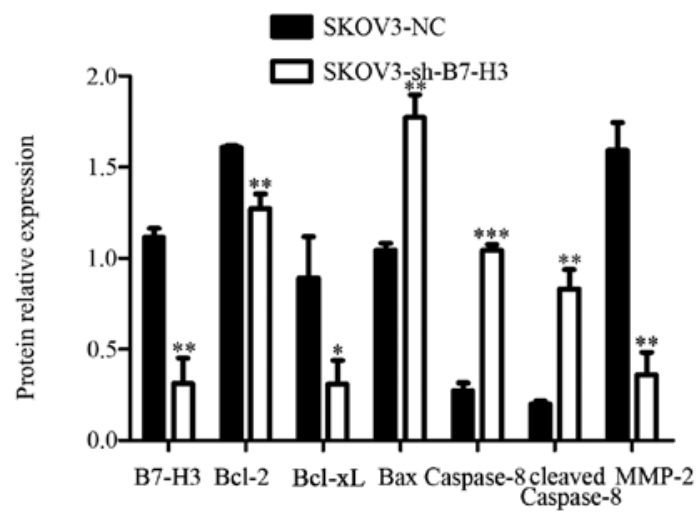

Figure 4. The changes of related protein molecules after silencing of B7-H3. (A and B) Western blot analysis for B7-H3 and after silencing B7-H3 the expression of anti-apoptotic proteins Bcl-2 and Bcl-xl and the pro-apoptotic protein Bax and caspase-8, cleaved caspase- 8 were measured by western blotting. $(\mathrm{C}$ and $\mathrm{D})$ Quantification of the protein expression levels as shown in $(\mathrm{E}$ and $\mathrm{F}) ;{ }^{*} \mathrm{P}<0.05,{ }^{* * *} \mathrm{P}<0.01,{ }^{* * * *} \mathrm{P}<0.001$ compared with the control groups.

the changes of apoptosis related proteins by the western blot method with the B7-H3 knockout. The results showed that with the silence of $\mathrm{B} 7-\mathrm{H} 3$ the expression of apoptosis regulator proteins of the Bcl-2 family, including the anti-apoptotic 

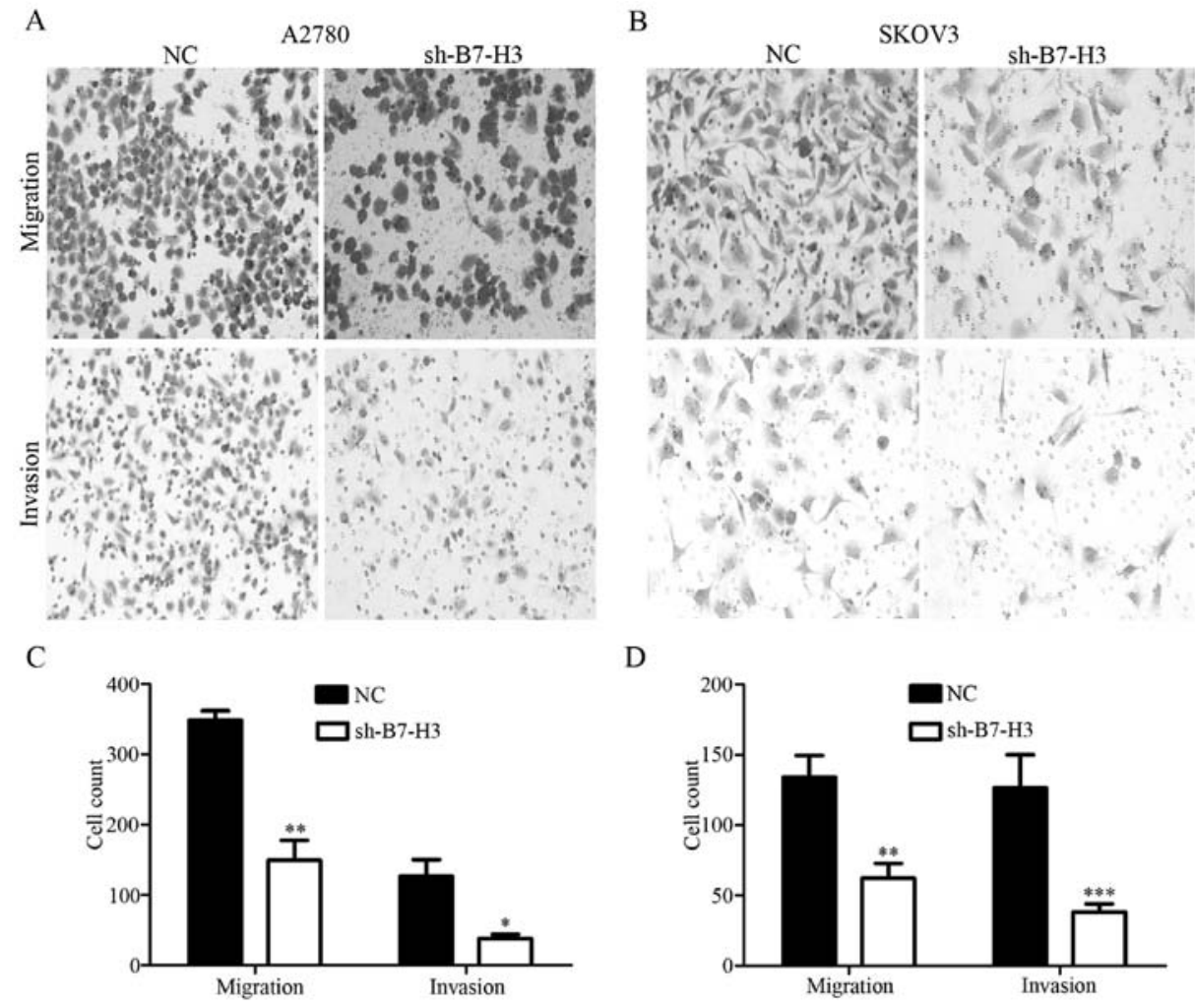

D

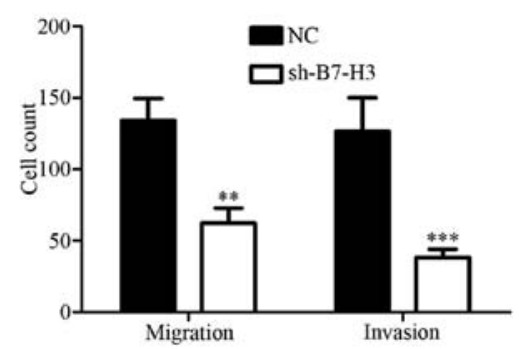

Figure 5. Silencing B7-H3 effects cell migration and invasion. (A and B) Silencing B7-H3 reduces the migration and invasion potential of A2780 and SKOV3 cell lines. (C and D) Quantification of the images of (A and $\mathrm{B}) ;{ }^{*} \mathrm{P}<0.05,{ }^{* * *} \mathrm{P}<0.01,{ }^{* * *} \mathrm{P}<0.001$ compared with the control groups.

A HO8910-NC

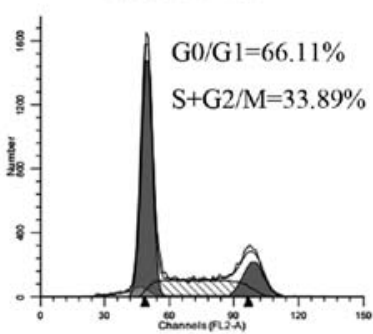

$\mathrm{C}$

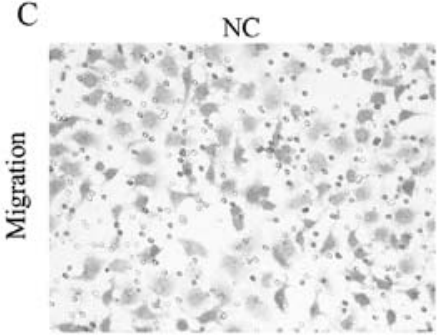

$\mathrm{E}$

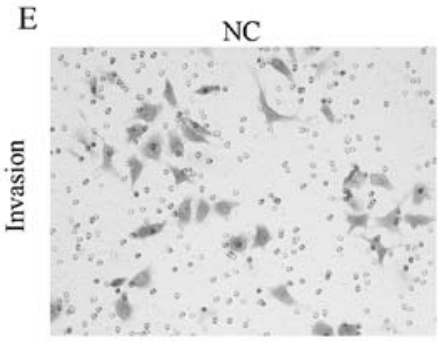

HO8910-B7-H3-EGFP
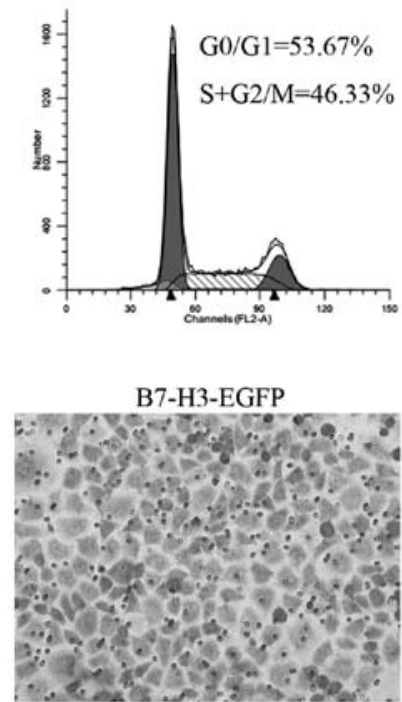

B7-H3-EGFP

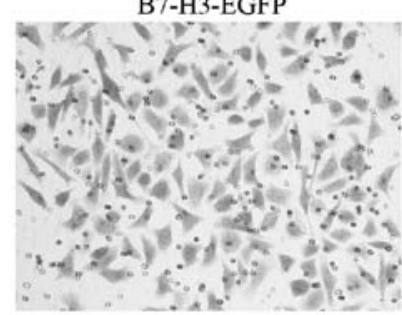

D
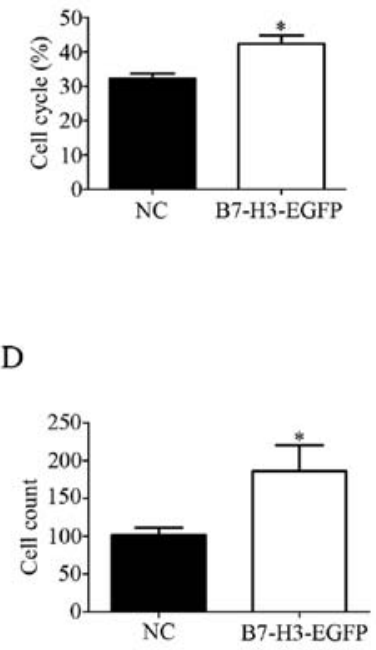

$\mathrm{F}$

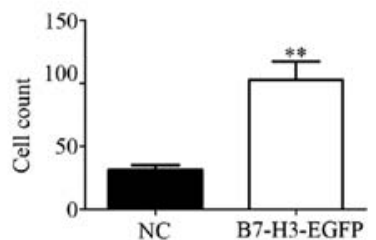

Figure 6. Effect of overexpression of B7-H3 on HO8910 cell line invasion, migration and proliferation. (A) Overexpression of B7-H3 in the HO8910 cell line increased the growth of cells that was analyzed by flow cytometry. (B) Quantification of the cell cycle. (C and E) Overexpression of B7-H3 effect on A2780 and SKOV3 cell migration and invasion by transwell chamber assay. (D and F) Quantification of the images of ( $\mathrm{D}$ and $\mathrm{E})($ magnification, $\mathrm{x} 200)$; ${ }^{*} \mathrm{P}<0.05,{ }^{* *} \mathrm{P}<0.01$, ${ }_{* * * *} \mathrm{P}<0.001$ compared with the control groups. 
A

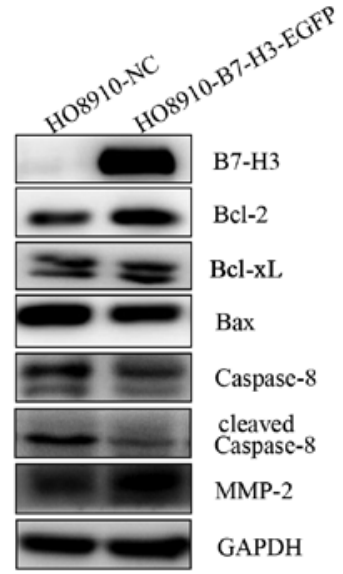

B

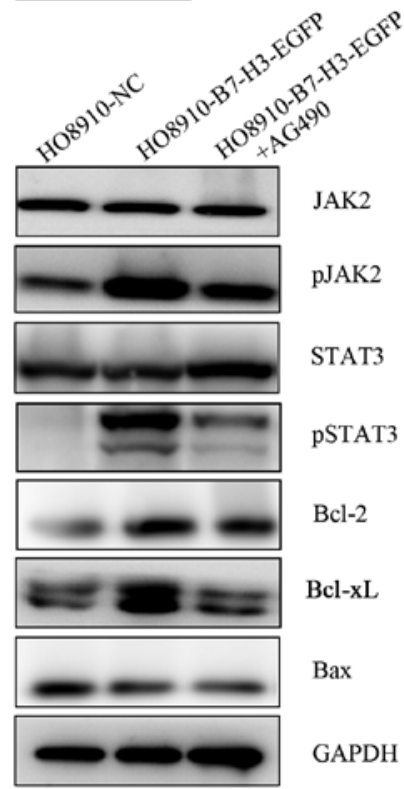

C

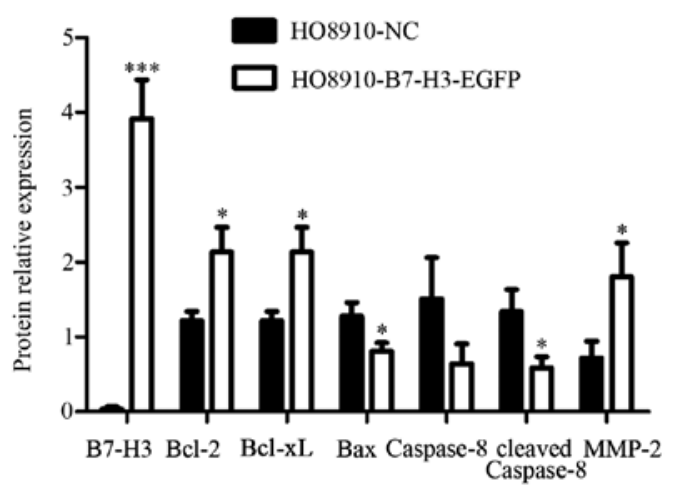

D

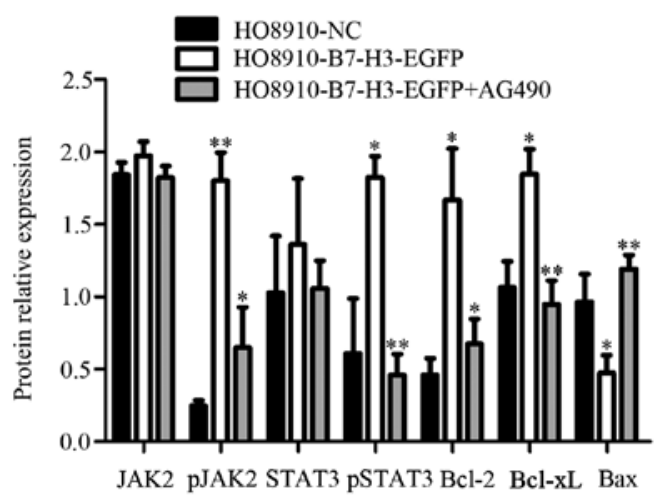

Figure 7. Overexpression of B7-H3 affects the expression of related protein molecules. (A) Western blot analysis of related proteins after B7-H3 overexpression (C) Comparison of relative protein levels from (A). (B) Expression of Jak2-Stat3 pathway proteins and apoptosis regulator proteins from the negative control cells (HO8910-NC), the B7-H3 overexpressing cells (HO8910-B7-H3-EGFP) to the AG490 treated B7-H3 overexpressing cells (HO8910-B7-H3EGFP+AG490) were performed by western blotting. (D) Quantification of the expresssion of relative proteins; ${ }^{*} \mathrm{P}<0.05,{ }^{* * *} \mathrm{P}<0.01,{ }^{* * * *} \mathrm{P}<0.001$ compared with the control groups.

proteins Bcl-2 and Bcl-xl decreased, while expression of the pro-apoptotic protein Bax, caspase- 8 and cleaved caspase- 8 increased (Fig. 4A and B). The expression of B7-H3 in ovarian cancer cells is closely related to apoptosis related molecules, which suggests that silencing B7-H3 may promote apoptosis of ovarian cancer cells.

Silencing $\mathrm{B}$ - $\mathrm{H} 3$ reduced the migration and invasion potential of ovarian cancer cells. We next further assessed the influence of B7-H3 on ovarian cancer cell migration and invasion by transwell assays. As shown in the results, compared with the control groups, the number of cells in migration passing through the chamber was significantly reduced in A2780-sh-B7-H3 group and SKOV3-sh-B7-H3 group (Fig. 5A and B). The same phenomenon was observed in the cell invasion test. Silencing B7-H3 can impede cell migration and inhibit cell invasion via downregulating the expression of MMP-2 (13). Thus, we measured the invasion related proteins by western blotting and found that MMP-2 were lower in A2780-sh-B7-H3 and SKOV3-sh-B7-H3 cells than in the $\mathrm{NC}$ groups (Fig. 4A and B). Based on these results, we come to the conclusion that the downregulation of $\mathrm{B} 7-\mathrm{H} 3$ expression could suppress cellular migration and invasion in human ovarian cancer cells.

Overexpression of B7-H3 enhances ovarian cancer cell invasion, migration and proliferation in vitro. We described above the effect of silencing B7-H3 in ovarian cancer cells. In order to further verify the role of B7-H3 in ovarian cancer cells, HO8910 cell line was overexpressed by lentivirus. Using cell cycle assay, we observed that the growth of HO8910B7-H3-EGFP was increased compared to NC cells (Fig. 6A and $\mathrm{B}$ ). Besides, we performed transwell assay and the result showed that overexpression of B7-H3 significantly increased the ability of cell migration and invasion (Fig. 6C and E). The expression of related protein MMP-2 was elevated with the overexpression of B7-H3 (Fig. 7A). The expression of B7-H3 and the anti-apoptotic proteins were positively correlated in CRC cell lines (6). Therefore, we found that the expression of protein Bcl-2, Bcl-xl added while Bax, caspase-8, cleaved 
caspase- 8 reduced by upregulation of $\mathrm{B} 7-\mathrm{H} 3$ expression (Fig. 7A). To summarize, overexpression of B7-H3 inhibits apoptosis and enhanced cell invasion, migration and proliferation in ovarian cancer cells.

Overexpression of $\mathrm{B} 7-\mathrm{H} 3$ affects the Jak2-Stat3 pathway. The role of B7-H3 in ovarian cancer cells is described above, therefore, we investigated which signaling pathway was involved in this process. The Jak2/Stat 3 pathway has been reported to be the key in cell migration, invasion and metastasis, and inhibition of Jak2/Stat 3 signaling induced CRC cell apoptosis, cell arrest and reduced tumor cell invasion (14-16). Thus, it was analyzed whether this pathway could be affected by B7-H3 in ovarian cancer. HO8910-B7-H3-EGFP cells were treated with AG490 with a concentration of $100 \mathrm{mmol} / 1$. After $48 \mathrm{~h}$, the protein expression of related molecules in Jak2/Stat 3 pathway was detected by western blotting. As shown in the chart, the phosphorylation levels of Jak2 and Stat 3 increased with the overexpression of B7-H3. However, when the cells were treated with AG490, the expression decreased correspondingly. Furthermore, anti-apoptotic proteins Bcl-2 and Bcl-xl increased while expression of the pro-apoptotic protein Bax was reduced following upregulated expression of B7-H3 and after joining the AG490 the results were exactly the opposite (Fig. 7B). These findings indicated that B7-H3 may participate and influence the Jak2/ Stat3 pathway in ovarian cancer cells. However, whether B7-H3 affects this pathway through activation or other ways, or not, needs further experimentation.

\section{Discussion}

B7-H3, as an immunoregulatory molecule, playing different roles in different types of human cancers (17). The role of B7-H3 in tumor immunity is complicated as both $\mathrm{T}$ cell co-stimulatory and co-inhibitory effects have been shown (18). In this study, we provide evidence that B7-H3 may be associated with tumor progression in ovarian cancer. In other words, B7-H3 probably plays a negative regulatory role in ovarian cancer.

In the past studies, only few scattered stromal cells in nonneoplastic ovarian tissues expressed B7-H3 $(3,19,20)$. Only one recent investigation showed that most ovarian cancers express B7-H3 (12). In this study, we further demonstrated that B7-H3 is highly expressed in patients with ovarian cancer, mainly in adenocarcinoma, but has no expression or low expression in normal epithelial ovarian tissues. The correlation between B7-H3 and the age, clinical stage, prognosis and other factors of patients with ovarian cancer was analyzed. The data suggest that B7-H3 expression is only associated with distant metastasis of ovarian cancer. We also found that B7-H3 was mainly expressed in the cytoplasm of ovarian cancer cells. To date, there are no published studies looking at the ability of B7-H3 to affect the growth of human ovarian cancer cell lines in vitro (21). Therefore, this study provides the basis how B7-H3 affects the biological behavior of ovarian cancer cell lines. Our study demonstrated that B7-H3 is closely associated with tumor progression in ovarian cancer cells. Silencing B7-H3 can attenuate the A270, SKOV3 cell lines of proliferation, migration and invasion and increase cell apoptosis, and induce changes in related molecules. On the contrary, overexpression of $\mathrm{B} 7-\mathrm{H} 3$ can increase the proliferation, migration and invasion of HO8910 cell line, and decrease the rate of apoptosis. The changes of protein molecules suggest that $\mathrm{B} 7-\mathrm{H} 3$ may be a potential therapeutic target for ovarian cancer.

The Jak2-Stat3 pathway plays a significant role in biological function on various human cancers. Zhang et al confirmed that the Jak2-Stat3 signaling pathway played an important role in regulating the anti-apoptotic ability of B7-H3 (6). Silenced B7-H3 expression suppresses migration and invasion of HCC cells via Jak2/SAtat3/Slug signaling pathway, which was proved by Kang et al (5). Stat3 regulates cellular differentiation, proliferation, migration and survival as a cytoplasmic transcription factor (22-25), which was regulated by its upstream molecule Jak2. Jak2-Stat3 are reported to be the downstream signaling pathways that adjust the ability of B7-H3 to regulate the expression of $\mathrm{Bcl}-2$, Bcl-xl, Bax and other molecules (6). In the present study, we found that after overexpression of B7-H3 the phosphorylation levels of Jak2 and Stat 3 increased. However, after treatment with AG490, which is the inhibitor of Jak2, the expression of anti-apoptotic proteins Bcl-2 and Bcl-xl and pro-apoptotic protein Bax also changed. The data indicate that B7-H3 enhanced proliferation and reduces apoptosis probably by influencing Jak2-Stat3 pathway. But how B7-H3 specifically influenced this pathway, needs further experiments to verify the mechanism.

In conclusion, results of this study identified that B7-H3 is related to tumor progression in ovarian cancer and probably can be used as an indicator in clinic in the future. The limitations are that we did not conduct animal experiments in this research due to the lack of experimental funds and the limitations of laboratory conditions. We consider this aspect well worth studying. As mentioned above, the specific role of B7-H3 and its mechanism need further studies.

\section{Acknowledgements}

The present study was funded by the National Natural Science Foundation of China (NSFC; 81572559), the Science and Technology Developing Planning of Shandong Province (2014GH218029) and the National Science and Technology Project of China (2015BAI13B05).

\section{References}

1. Siegel RL, Miller KD and Jemal A: Cancer statistics, 2016. CA Cancer J Clin 66: 7-30, 2016.

2. Siegel R, Naishadham D and Jemal A: Cancer statistics, 2012. CA Cancer J Clin 62: 10-29, 2012.

3. Chapoval AI, Ni J, Lau JS, Wilcox RA, Flies DB, Liu D, Dong H, Sica GL, Zhu G, Tamada K, et al: B7-H3: A costimulatory molecule for $\mathrm{T}$ cell activation and IFN-gamma production. Nat Immunol 2: 269-274, 2001.

4. Dong C, Nurieva RI and Prasad DV: Immune regulation by novel costimulatory molecules. Immunol Res 28: 39-48, 2003.

5. Kang FB, Wang L, Jia HC, Li D, Li HJ, Zhang YG and Sun DX: $\mathrm{B} 7-\mathrm{H} 3$ promotes aggression and invasion of hepatocellular carcinoma by targeting epithelial-to-mesenchymal transition via JAK2/STAT3/Slug signaling pathway. Cancer Cell Int 15: 45, 2015.

6. Zhang T, Jiang B, Zou S-T, Liu F and Hua D: Overexpression of B7-H3 augments anti-apoptosis of colorectal cancer cells by Jak2-STAT3. World J Gastroenterol 21: 1804-1813, 2015. 
7. Kang FB, Wang L, Li D, Zhang YG and Sun DX: Hepatocellular carcinomas promote tumor-associated macrophage M2-polarization via increased B7-H3 expression. Oncol Rep 33: 274-282, 2015

8. Jin Y, Zhang P, Li J, Zhao J, Liu C, Yang F, Yang D, Gao A, Lin W, Ma X, et al: B7-H3 in combination with regulatory $\mathrm{T}$ cell is associated with tumor progression in primary human non-small cell lung cancer. Int J Clin Exp Pathol 8: 13987-13995, 2015.

9. Dai W, Shen G, Qiu J, Zhao X and Gao Q: Aberrant expression of B7-H3 in gastric adenocarcinoma promotes cancer cell metastasis. Oncol Rep 32: 2086-2092, 2014.

10. Sun J, Guo YD, Li XN, Zhang YQ, Gu L, Wu PP, Bai GH and Xiao Y: B7-H3 expression in breast cancer and upregulation of VEGF through gene silence. Onco Targets Ther 7: 1979-1986, 2014.

11. Yuan H, Wei X, Zhang G, Li C, Zhang X and Hou J: B7-H3 over expression in prostate cancer promotes tumor cell progression. J Urol 186: 1093-1099, 2011

12. Zang X, Sullivan PS, Soslow RA, Waitz R, Reuter VE, Wilton A Thaler HT, Arul M, Slovin SF, Wei J, et al: Tumor associated endothelial expression of $\mathrm{B} 7-\mathrm{H} 3$ predicts survival in ovarian carcinomas. Mod Pathol 23: 1104-1112, 2010.

13. Zhang W, Wang Y, Wang J, Dong F, Zhu M, Wan W, Li H, Wu F, Yan X and Ke X: B7-H3 silencing inhibits tumor progression of mantle cell lymphoma and enhances chemosensitivity. Int $\mathbf{J}$ Oncol 46: 2562-2572, 2015.

14. Du W, Hong J, Wang YC, Zhang YJ, Wang P, Su WY, Lin YW, Lu R, Zou WP, Xiong $\mathrm{H}$, et al: Inhibition of JAK2/STAT3 signalling induces colorectal cancer cell apoptosis via mitochondrial pathway. J Cell Mol Med 16: 1878-1888, 2012.

15. Xiong H, Chen ZF, Liang QC, Du W, Chen HM, Su WY, Chen GQ, Han ZG and Fang JY: Inhibition of DNA methyltransferase induces G2 cell cycle arrest and apoptosis in human colorectal cancer cells via inhibition of JAK2/STAT3/STAT5 signalling. J Cell Mol Med 13: 3668-3679, 2009.
16. Xiong H, Zhang ZG, Tian XQ, Sun DF, Liang QC, Zhang YJ, Lu R, Chen YX and Fang JY: Inhibition of JAK1, 2/STAT3 signaling induces apoptosis, cell cycle arrest, and reduces tumor cell invasion in colorectal cancer cells. Neoplasia 10: 287-297, 2008.

17. Wang Z-S, Zhong M, Bian Y-H, Mu Y-F, Qin S-L, Yu M-H and Qin J: MicroRNA-187 inhibits tumor growth and invasion by directly targeting CD276 in colorectal cancer. Oncotarget 7: 44266-44276, 2016.

18. zur Hausen H: Papillomaviruses and cancer: From basic studies to clinical application. Nat Rev Cancer 2: 342-350, 2002.

19. Sica GL, Choi IH, Zhu G, Tamada K, Wang SD, Tamura H, Chapoval AI, Flies DB, Bajorath J and Chen L: B7-H4, a molecule of the B7 family, negatively regulates $\mathrm{T}$ cell immunity. Immunity 18: 849-861, 2003.

20. Tringler B, Zhuo S, Pilkington G, Torkko KC, Singh M, Lucia MS, Heinz DE, Papkoff J and Shroyer KR: B7-h4 is highly expressed in ductal and lobular breast cancer. Clin Cancer Res 11: 1842-1848, 2005.

21. Fauci JM, Straughn JM Jr, Ferrone S and Buchsbaum DJ: A review of B7-H3 and B7-H4 immune molecules and their role in ovarian cancer. Gynecol Oncol 127: 420-425, 2012.

22. Liu H, Tekle C, Chen Y-W, Kristian A, Zhao Y, Zhou M, Liu Z, Ding Y, Wang B, Mælandsmo GM, et al: B7-H3 silencing increases paclitaxel sensitivity by abrogating Jak2/Stat 3 phosphorylation. Mol Cancer Ther 10: 960-971, 2011.

23. Levy DE and Darnell JE Jr: Stats: Transcriptional control and biological impact. Nat Rev Mol Cell Biol 3: 651-662, 2002.

24. Levy DE and Inghirami G: STAT3: A multifaceted oncogene. Proc Natl Acad Sci USA 103: 10151-10152, 2006.

25. Schlessinger K and Levy DE: Malignant transformation but not normal cell growth depends on signal transducer and activator of transcription 3. Cancer Res 65: 5828-5834, 2005. 